\title{
Building learning organizational culture during COVID-19 outbreak: a national study
}

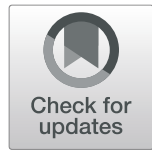

Wadi B. Alonazi

\begin{abstract}
Background: Hospitals and healthcare institutions should be observant of the ever-changing environment and be adaptive to learning practices. By adopting the steps and other components of organizational learning, healthcare institutions can convert themselves into learning organizations and ultimately strengthen the overall healthcare system of the country. The present study aimed to examine the influence of several organizational learning dimensions on organization culture in healthcare settings during the COVID-19 outbreak.

Methods: During COVID-19 crisis in 2020, an online cross-sectional study was performed. Data were collected via official emails sent to 1500 healthcare professionals working in front line at four sets of hospitals in Saudi Arabia. Basic descriptive analysis was constructed to identify the variation between the four healthcare organizations. A multiple regression was employed to explore how hospitals can adopt learning process during pandemics, incorporating several Dimensions of Learning Organizations Questionnaire (DLOQ) developed by Marsick and Watkins (2003) and Leufvén and others (2015).

Results: Organizational learning including system connections $(M=3.745)$, embedded systems $(M=3.732)$, and team work and collaborations $(M=3.724)$ tended to have major significant relationships with building effective learning organization culture. Staff empowerment, dialogues and inquiry, internal learning culture, and continuous learning had the lowest effect on building health organization culture $(M=3.680, M=3.3 .679, M=3.673, M=3.663$, respectively). A multiple linear regression was run to predict learning organization based on the several variables. These variables statistically significantly predicted learning organization, $F(6,1124)=168.730, p<.0005, R^{2}=0.471,(p<.05)$.

Discussion: The findings concluded that although intrinsic factors like staff empowerment, dialogues and inquiry, and internal learning culture, revealed central roles, still the most crucial factors toward the development of learning organization culture were extrinsic ones including connections, embed system and collaborations.

Conclusions: Until knowledge-sharing is embedded in health organizational systems; organizations may not maintain a high level of learning during crisis.
\end{abstract}

Keywords: Learning organization, Culture, Knowledge-share, COVID-19 outbreak

Correspondence: waalonazi@ksu.edu.sa

Health Administration Department, College of Business Administration, King

Saud University, PO Box 71115, 11587 Riyadh, Saudi Arabia

(c) The Author(s). 2021 Open Access This article is licensed under a Creative Commons Attribution 4.0 International License, which permits use, sharing, adaptation, distribution and reproduction in any medium or format, as long as you give appropriate credit to the original author(s) and the source, provide a link to the Creative Commons licence, and indicate if changes were made. The images or other third party material in this article are included in the article's Creative Commons licence, unless indicated otherwise in a credit line to the material. If material is not included in the article's Creative Commons licence and your intended use is not permitted by statutory regulation or exceeds the permitted use, you will need to obtain permission directly from the copyright holder. To view a copy of this licence, visit http://creativecommons.org/licenses/by/4.0/ The Creative Commons Public Domain Dedication waiver (http://creativecommons.org/publicdomain/zero/1.0/) applies to the data made available in this article, unless otherwise stated in a credit line to the data. 


\section{Background}

Having a primary role in restoring and maintaining wellbeing, healthcare systems largely depend on organizations, people, and their competencies [1]. Particularly, performance of healthcare systems varies based on the structure, process and expected outcomes [2]. On a micro level, healthcare organizations such as hospitals and medical institutions remain at the nucleus of the healthcare system regardless of the type of funding and structure and the provided services to the general population [1]. The key indicator of hospital performance is the safe and consistent services provided to patients by medical and non-medical staff [3]. Therefore, coordination and communication within and between the teams is a must to develop cohesive functioning essential to provide high quality of medical care [4]. Healthcare organizations are always bound to modify their functioning due to dramatic changes in prevalence of diseases and pandemics without compromising the quality of services [5]. Acquiring advanced technologies and creation and utilization of contemporary knowledge can help healthcare organizations to perform well.

Learning organization is considered as a cumulative phenomenon facilitating personal and professional growth of individuals and teams. It also develops collective learning in an organization that leads to enhance individual as well as organizational performance [6]. Indeed, learning organization improves the efficiency and effectiveness of an organization through shared knowledge [7]. An organization that practices continuous learning of employees, bound to transform itself where employees continuously create, acquire, and share knowledge is called learning organization [8]. Learning organization and organizational learning has been used interchangeably in previous literature. However, there is a thin line which differentiates the two. According to Preskill and Torres learning organization focuses on characteristics, principles, and systems whereas organizational learning emphasizes on the process of learning [9]. However, in each level, individuals are the main agents that involve in learning organization or organizational learning and bring substantial changes. Ultimately, organizational learning is a process through which an organization develops new knowledge and understands from routine experiences of the employees. Organizational learning has the potential to change the behavior of employees and improve the organizational capability on policy and practical levels [10].

Learning organization is the first step towards obtaining dynamic knowledge that brings change among employees, whereas in the context of a learning organization, knowledge is acquired and shared among employees via a system that develops capacity to improve performance [10]. Generally, learning organization is influenced by contextual factors such as culture. An organization that regards learning as absolutely critical for its business success is considered well-equipped with knowledge culture [11]. Organizational culture is the characteristic of an organization which manifests the sharing of common values and beliefs among its employees [12]. Thus, learning organization culture develops skills within an organization to create, acquire, and transfer knowledge and enhance positive behavior to follow new medical practice or guidelines [13].

As changing environment forces every healthcare organization to enhance quality and safety, practice of learning organization can improve the knowledge and skills of medical staff and guide them to find better ways to work effectively [14]. Collective learning among small groups or teams could lead to standard performance of healthcare organization through shared knowledge and better understanding among teams [15]. In the context of healthcare services, members of the teams may convert their knowledge in actions and later evaluate actions on evidence based practice associated with contemporary guidelines [7]. Reay and others argued that in healthcare services, physicians and managers first choose the correct knowledge from existing ones and adapt the knowledge to solve problems and find solutions at hand. This process can help in managing conflicts between management and medical professionals. The process of learning in healthcare is time consuming; yet it provides the precise way to cope with medical crises [16].

\section{Components of Health Learning Organization culture}

The early studies on learning organization focused on five factor model developed by Senge including systems thinking, personal mastery, mental models, building a shared vision, and team learning [17]. Gomes and Wojahn conceptualized learning organization on the basis of four components as experimentation, interaction, risk, and dialogue, but concluded that learning organizations had the capability to improve innovation performance [18]. Additionally, Halim and others included three components of learning organization as information acquisition, information interpretation, and behavioral and cognitive and initiated an imperative role of these factors in innovation culture and performance [19].

In the context of healthcare organization, Leuven and colleagues developed seven dimensions that measure organizational learning in low resources healthcare settings [4]. These seven dimensions are continuous learning, dialogue and inquiry, team learning and collaboration, embedded systems, empowerment, systems connections, and strategic leadership. Previous studies on organizational learning in healthcare settings included all top, middle, and lower level employees as part of the study $[4,20,21]$. However, a little is focused on the role of healthcare professionals during crisis to create 
an environment of organizational learning. During crisis, knowledge management is complex due to the fact that various networks apply different strategies like centralization and other organizational structure like independency [22]. Therefore, the study excluded the dimension of strategic learning in conceptualization of strategic learning mainly focus on support of leadership on learning and leadership models.

\section{Promoting organizational learning during crisis}

Creating, retaining, and transferring useful knowledge are key elements when health institutions incorporate a new model for corporate learning and development [23]. During crisis, medical institutions take a few effective staff in formal committee to accelerate the process ahead of other activity, projecting the less risky roads. Building health protocols, ensuring its effectiveness, as well as revealing the practice among healthcare professionals was a major goal to deal with COVID-19. Again, what promotes organizational learning is the nature of the emergency, which is in this case a pandemic issue [24].

Though the Saudi government issued instructions to lockdowns, self-isolation, and social distancing, such instructions were initiated based on international learning system, mostly from the World Health Organization (WHO), as well we as the internal experience [25]. However, $\mathrm{MOH}$ has taken effective steps in almost each hospital to prevent the spread of the viruses. The $\mathrm{MOH}$ initiated on online medical consultations and many activities to learn from this anise. Figure 1 shows the number of new, infected, and death cases in Saudi Arabia during the study period.

\section{Saudi healthcare system}

In Saudi Arabia, the healthcare system is at cross roads where the old publicly funded system, regulated mainly by the government, is now under transition period to be privatized with less power of the government [5]. Almost two-thirds of health provisions are funded by the government, under the regulation of the Ministry of Health. Semi-government agencies like Ministry of Defense, Ministry of Guard and Ministry of Interior contribute also in funding their health settings [26]. Despite such services by the government, private sector and university hospitals contribute slightly in operating the Saudi healthcare system. Again, social reform is an integral part to effective health improvement [27]. As the government is under heavy transition periods by the new health leadership, it is expected the funding portion is flipped within decades [5, 28]. As a result of each provision having different entities and priorities, a chasm now may exist between knowledge and practice within each entity [29].

Having several healthcare providers, the learning organization culture of each entity across the country has not been well-studied [30]. However, learning organization is necessary to implement the strategies that could benefit the organization. In addition, working productivity is also dependent on improved working efficiency and environment that are by products of organization learning [31]. Understanding learning organization culture in such contexts would enhance the resilience of the Saudi system and may enable it to better absorb the adverse effects of the economic and political shocks, especially under such transition periods.

\section{Methods}

This is a cross-sectional study where the overriding objective was to explore some domains associated with building effective organization learning culture during crisis.

\section{Tool}

Consisting of 21 items, the abbreviated form of Dimensions of Learning Organizations Questionnaire (DLOQ)

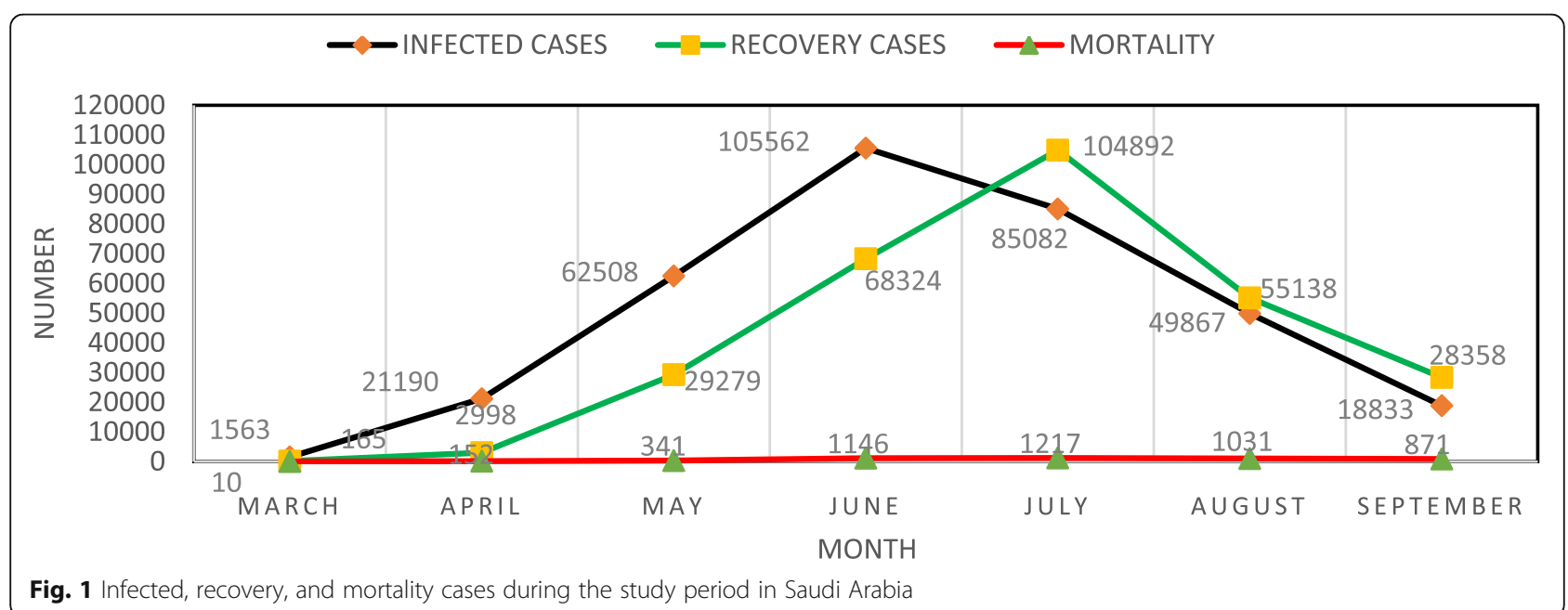

Fig. 1 Infected, recovery, and mortality cases during the study period in Saudi Arabia 
developed by Marsick and Watkins [32] and Leuve was utilized in this study. The purpose of using this tool was simply because it possessed construct validity and sound reliability. Three adequate measurement items (individual, group, and organization) for each dimension included in this study.

\section{Data Collection}

During March to September 2020, data were collected from four major healthcare providers including Ministry of Health (MOH), Teaching University Hospital (TUH), Semi Government (SGH), and Private Hospitals (PH). During partial lockdown, an on line survey was sent to some corporate communication departments to liaise the survey, after obtaining the IRB. The unit of analysis was the first line of healthcare workers who directly deal with COVID-19 cases. The judgmental sampling method was used to identify the eligible respondents and data were collected through electronic mails.

\section{Procedure and sampling}

This study used G*power software to calculate the minimum sample size as recommended by Hair and others for PLS-SEM analysis and found minimum sample of 146 was adequate as maximum six predictors pointing at one endogenous variable [33]. Medium effect size and 0.95 power of the model were set for calculation. The sample size of 1131 of the study satisfied the condition of minimum sample size.

\section{Measurement}

All items of the constructs were adapted from the existing literature and were slightly modified to fulfill the objective of the study [4, 32]. All the items were measured on a five-point Likert scale that ranged from (1) strongly disagree to (5) strongly agree.

\section{Results}

Out of 1500 assigned emails, only 1131 responses returned as they were used for final data analysis. In regard to learning environment, government, and semigovernment healthcare settings tend to provide better learning environment than private hospitals. As, from the total respondents of government, $95.6 \%$; semigovernment, 96.1\%; and university hospitals, $94.3 \%$ responded that the hospital in which they work is a real learning organization. However, in case of private hospitals $88.9 \%$ of the total respondents confirmed that the hospital is a learning organization as shown in Table 1.

The representation of the respondents was almost equally distributed from all four categories regarding their work nature in the hospitals i.e., government hospitals (24.2\%), university hospitals (21.6\%), semi-government hospitals (29.4\%), and private hospitals (24.8), as shown in Table 2.

As shown in Table 3, teaching university hospital (TUH) indicated the highest level in building learning organization among the rest, with the highest level in effective system connection and the lowest in continuous learning process. The lowest level in building learning organization was the private Health Hospitals $(\mathrm{PH})$, in the highest score of system connections and the lowest in building internal continues learning and equally building the culture of learning $(M=3.13$, and $M=2.95$, respectively).

In Table 4, a correlation matrix was constructed to measure the strength between the intrinsic and extrinsic variables when building effective learning organization during crisis.

A multiple linear regression (MLR) was constructed to model the linear relationship between the explanatory variables and building effective organizational culture in the assigned settings. As shown in Table 5 , a significant regression equation was found $(F(6,1124)=168.730$, $p<.0005, R^{2}=0.471$ ).

We can estimate the model to build effective learning organization during COVID-19 crisis, knowing the values for the six variables, by using the regression model:

$$
\mathrm{SL}=0.340+0.152 \quad(\mathrm{CL})+0.096 \quad(\mathrm{DI})+0.100 \quad(\mathrm{TC})+
$$
$0.180(\mathrm{ES})+0.136(\mathrm{EM})+0.235(\mathrm{SC})$.

All six variables are significant predictors of learning organization. $P$-values $<0.05$ and even 0.01 for all the variables. The result explained that the internal system and connections were superior, compared to other methods. As shown, the $R^{2}$ value for learning organization culture of 0.475 suggests that $47.5 \%$ of the variance of

Table 1 Responses about the possibility of having organization as a place of learning

\begin{tabular}{|c|c|c|c|c|c|c|c|c|c|c|c|}
\hline \multirow{3}{*}{\multicolumn{2}{|c|}{$\begin{array}{l}\text { Is this hospital } \\
\text { considered a } \\
\text { learning } \\
\text { organization? }\end{array}$}} & \multicolumn{10}{|c|}{ Hospital Type $^{a}$} \\
\hline & & \multicolumn{2}{|l|}{$\mathrm{MOH}$} & \multicolumn{2}{|l|}{ TUH } & \multicolumn{2}{|l|}{ SGH } & \multicolumn{2}{|l|}{$\mathrm{PH}$} & \multicolumn{2}{|l|}{ Overall } \\
\hline & & $n=274$ & $\%$ & $n=244$ & $\%$ & $n=333$ & $\%$ & $n=\mathbf{2 8 0}$ & $\%$ & $n=1131$ & $\%$ \\
\hline \multirow[t]{2}{*}{ Male } & Yes & 131 & 48 & 121 & 50 & 174 & 52 & 141 & 50 & 567 & 50.1 \\
\hline & No & 7 & 2 & 7 & 3 & 8 & 2 & 16 & 6 & 38 & 3.4 \\
\hline \multirow[t]{2}{*}{ Female } & Yes & 131 & 48 & 109 & 45 & 146 & 44 & 108 & 39 & 494 & 43.7 \\
\hline & No & 5 & 2 & 7 & 3 & 5 & 2 & 15 & 5 & 32 & 2.8 \\
\hline
\end{tabular}

${ }^{\mathrm{a}} \mathrm{MOH}$ Ministry of Health, TUH Teaching University Hospital, SGH Semi-governmental Hospital, $P H$ Private Hospital 
Table 2 The demographic characteristics of the participants and their career background

\begin{tabular}{|c|c|c|c|c|c|c|c|c|c|c|}
\hline \multirow{3}{*}{\multicolumn{2}{|c|}{$\begin{array}{l}\text { The nature of the } \\
\text { respondents' work }\end{array}$}} & \multicolumn{9}{|c|}{ Hospital Type $^{a}$} \\
\hline & & \multicolumn{3}{|c|}{$\mathrm{MOH}$} & \multicolumn{2}{|l|}{ TUH } & \multicolumn{2}{|l|}{ SGH } & \multicolumn{2}{|l|}{$\mathrm{PH}$} \\
\hline & & $n=2$ & & $\%$ & $n=244$ & $\%$ & $n=333$ & $\%$ & $n=280$ & $\%$ \\
\hline \multirow[t]{6}{*}{ Yes } & Clinical & $M$ & 49 & 18 & 77 & 32 & 62 & 19 & 62 & 22 \\
\hline & & $\mathrm{F}$ & 42 & 15 & 74 & 30 & 42 & 13 & 49 & 18 \\
\hline & Administrative & M & 62 & 23 & 33 & 14 & 94 & 28 & 71 & 25 \\
\hline & & $\mathrm{F}$ & 68 & 25 & 27 & 11 & 74 & 22 & 50 & 18 \\
\hline & Both & M & 20 & 7.3 & 11 & 4.5 & 18 & 5.4 & 8 & 2.9 \\
\hline & & $\mathrm{F}$ & 21 & 7.7 & 8 & 3.3 & 30 & 9 & 9 & 3.2 \\
\hline \multirow[t]{6}{*}{ No } & Clinical & M & 2 & 0.7 & 5 & 2 & 2 & 0.6 & 9 & 3.2 \\
\hline & & $\mathrm{F}$ & 0 & 0 & 6 & 2.5 & 1 & 0.3 & 8 & 2.9 \\
\hline & Administrative & M & 5 & 1.8 & 2 & 0.8 & 4 & 1.2 & 4 & 1.4 \\
\hline & & $\mathrm{F}$ & 4 & 1.5 & 1 & 0.4 & 3 & 0.9 & 5 & 1.8 \\
\hline & Both & M & 0 & 0 & 0 & 0 & 2 & 0.6 & 3 & 1.1 \\
\hline & & $\mathrm{F}$ & 1 & 0.4 & 0 & 0 & 1 & 0.3 & 2 & 0.7 \\
\hline
\end{tabular}

${ }^{\mathrm{a}} \mathrm{MOH}$ Ministry of Health, $\mathrm{TUH}$ Teaching University Hospital, SGH Semi-governmental Hospital, $P H$ Private Hospital, $Y$ Yes, $N$ No, $M$ Male, $F$ Female

learning organization culture can be explained by six independent variables. The structural model represents the assumed relationship between some variables [33]. The results revealed that continuous learning, dialogues and inquiry, team learning and collaboration, embedded systems, empowerment, and systems connections all have significant positive relationship with learning organization culture.

\section{Discussion}

The aim of the study was to examine the factors influencing building effective learning organization culture in various healthcare. Having theoretical and practical implications, this study bridges the gap in literature on learning organization culture in healthcare settings. Besides, study findings guide top management of the hospitals and policy makers to develop policies and guidelines based on organization learning that create cohesive work environment among various departments of hospitals to provide quality services to patients. Becoming a learning organization is complex and provider-based specific. Unlike process and outcomes indicators, the structural indicators have influence on formulating effective health learning organization culture [34].

First, structural indicators including system connections, embedded system and team work were reported to have a major influence on learning organization. Indeed, the structural components of the health organization have the strongest relationship in formulating health learning organization culture. Systems connections explain that an organization must observe a problem from different aspects and encourage employees to engage across the organization and with outside environment to bring solutions [17]. Unlike European health settings, hospitals in Asian countries, generally, lack practice of engaging the general population to develop new ideas and learning $[35,36]$.

Collaboration with community welfare organizations, local health agencies, and health consultants can bring advanced knowledge to hospitals and guide in

Table 3 Results of descriptive analysis including the mean of each setting

\begin{tabular}{lllll}
\hline Latent Construct/Item & $\begin{array}{l}\text { MOH } \\
(\boldsymbol{n = 2 7 5 )}\end{array}$ & $\begin{array}{l}\text { TUH } \\
(\boldsymbol{n}=\mathbf{2 4 4})\end{array}$ & $\begin{array}{l}\text { SGH } \\
(\boldsymbol{n}=\mathbf{3 3 3})\end{array}$ & PH (n= 280) \\
\hline Continuous Learning (CL) & 3.12 & 4.11 & 4.37 & 2.95 \\
Dialogue and Inquiry (DI) & 3.00 & 4.37 & 4.27 & 3.03 \\
Team Learning and Collaboration (TC) & 3.16 & 4.35 & 4.32 & 3.02 \\
Embedded Systems (ES) & 3.27 & 4.38 & 4.25 & 3.00 \\
Empowerment (EM) & 3.01 & 4.35 & 4.27 & 3.05 \\
Systems Connections (SC) & 3.15 & 4.42 & 4.26 & 3.13 \\
Learning Organization Culture (SL) & 3.07 & 4.38 & 4.26 & 2.95 \\
Over all & 3.11 & 4.34 & 4.29 & 3.02 \\
\hline
\end{tabular}


Table 4 Correlation matrix to measure the strength between the intrinsic and extrinsic variables

\begin{tabular}{|c|c|c|c|c|c|c|c|c|}
\hline \multicolumn{2}{|c|}{ Domain/ Statistical Value } & \multirow{2}{*}{$\frac{S \mathbf{S}}{1}$} & \multirow[t]{2}{*}{$\mathrm{CL}$} & \multirow[t]{2}{*}{ DI } & \multirow[t]{2}{*}{ TC } & \multirow[t]{2}{*}{ ES } & \multirow[t]{2}{*}{ EM } & \multirow[t]{2}{*}{ SC } \\
\hline$\overline{S L}$ & $P$ & & & & & & & \\
\hline & Sig. & & & & & & & \\
\hline \multirow[t]{2}{*}{$\mathrm{CL}$} & P & $0.507^{\mathrm{a}}$ & 1 & & & & & \\
\hline & Sig. & 0.000 & & & & & & \\
\hline \multirow[t]{2}{*}{$\mathrm{DI}$} & $\mathrm{P}$ & $0.523^{a}$ & $0.547^{\mathrm{a}}$ & 1 & & & & \\
\hline & Sig. & 0.000 & 0.000 & & & & & \\
\hline \multirow[t]{2}{*}{$\mathrm{TC}$} & P & $0.535^{\mathrm{a}}$ & $0.483^{\mathrm{a}}$ & $0.580^{\mathrm{a}}$ & 1 & & & \\
\hline & Sig. & 0.000 & 0.000 & 0.000 & & & & \\
\hline \multirow[t]{2}{*}{ ES } & $\mathrm{P}$ & $0.539^{\mathrm{a}}$ & $0.472^{\mathrm{a}}$ & $0.523^{\mathrm{a}}$ & $0.592^{\mathrm{a}}$ & 1 & & \\
\hline & Sig. & 0.000 & 0.000 & 0.000 & 0.000 & & & \\
\hline \multirow[t]{2}{*}{ EM } & $\mathrm{P}$ & $0.540^{\mathrm{a}}$ & $0.486^{\mathrm{a}}$ & $0.548^{\mathrm{a}}$ & $0.587^{\mathrm{a}}$ & $0.526^{\mathrm{a}}$ & 1 & \\
\hline & Sig. & 0.000 & 0.000 & 0.000 & 0.000 & 0.000 & & \\
\hline \multirow[t]{2}{*}{ SC } & $\mathrm{P}$ & $0.572^{\mathrm{a}}$ & $0.487^{\mathrm{a}}$ & $0.553^{\mathrm{a}}$ & $0.565^{\mathrm{a}}$ & $0.505^{\mathrm{a}}$ & $0.584^{\mathrm{a}}$ & 1 \\
\hline & Sig. & 0.000 & 0.000 & 0.000 & 0.000 & 0.000 & 0.000 & \\
\hline
\end{tabular}

${ }^{a}$ Correlation is significant at the 0.01 level (2-tailed)

implementing strategies to overcome challenges faced by the hospitals. Team learning is a situation where individuals think together, share experiences, knowledge and skills to do the things in better way [17]. Hospital management and policy makers could promote a culture of engagement of employees within an extrinsic-intrinsic environment and share new knowledge across the organization for continuous learning. Acquired knowledge incorporated from outsiders but embedded in the working systems, practices, and structures can be used and shared to improve performance [32]. In healthcare settings, the learning acquired from the new knowledge should be deep rooted and become part of daily operations of the hospitals.

Empowerment, dialogue and inquiry, internal and continues learning philosophy were also positively related to learning organization culture. Empowerment is a process in which employees of every level take part in collective decision making and accountability. This practice develops motivation among employees to acquire new knowledge so that they can take better decisions [32]. However, in healthcare settings empowering every employee to a level where $\mathrm{s} / \mathrm{he}$ becomes a part of collective decision making is a huge challenge. Healthcare systems all across the world are predominantly governed by bureaucracy and hierarchical structure with set rules and operating procedures and left no room for many employees to be a part of decision making $[37,38]$. Employees, both medical and non-medical, remain excluded in decision-making but bound to implement the instruction and guidelines with high perfection. Policy makers and top administration must ensure the inclusion of hospital employees of every level in collective decision making so that they can also become part of learning and contribute to growth of healthcare system. Dialogues and inquiry are the reasoning skills to express views and the capacity to listen and inquire about the views of others [32]. Logical reasoning and dialogues open space for critical thinking and bring logical and appropriate solutions to different situations.

Continuous learning was also found strongly related to learning organization culture. In healthcare services,

Table 5 Summary of MLR analysis for variables predicting building effective leaning organizational culture

\begin{tabular}{|c|c|c|c|c|c|}
\hline \multirow[t]{2}{*}{ Model } & \multicolumn{2}{|c|}{ Unstandardized Coefficients } & \multirow{2}{*}{$\begin{array}{l}\text { Standardized Coefficients } \\
\text { Beta }\end{array}$} & \multirow[t]{2}{*}{$\mathbf{t}$} & \multirow[t]{2}{*}{ Sig. } \\
\hline & B & Std. Error & & & \\
\hline Constant & 0.340 & 0.107 & & 3.179 & 0.002 \\
\hline $\mathrm{CL}$ & 0.152 & 0.028 & 0.151 & 5.459 & 0.000 \\
\hline $\mathrm{Dl}$ & 0.096 & 0.031 & 0.094 & 3.117 & 0.002 \\
\hline $\mathrm{TC}$ & 0.100 & 0.032 & 0.097 & 3.099 & 0.002 \\
\hline ES & 0.180 & 0.029 & 0.177 & 6.119 & 0.000 \\
\hline EM & 0.136 & 0.031 & 0.134 & 4.427 & 0.000 \\
\hline SC & 0.235 & 0.031 & 0.224 & 7.545 & 0.000 \\
\hline
\end{tabular}


skills and knowledge can easily be outdated due to evolvement of technology and procedures. Therefore, medical and non-medical staffs must engage in continuous learning for their self-satisfaction and overall quality of healthcare services. However, researchers argued that continuous learning at individual level is important but not sufficient to improve performance unless and until not embedded in systems [32]. Hospital management may ensure that learning is not limited to individuals only and installed as part of systems so that teams and individuals can use it uninterruptedly.

Internal learning indicators were among the least important aspects to develop culture of learning in hospitals and healthcare institutions. However, in most of the Asian work settings expressing views openly and freely is unwelcoming among colleagues and superiors. This is again mainly due to bureaucracy and hierarchical nature of functioning in healthcare systems [22]. Giving voice to every individual to express their reasoning and logical thinking in healthcare institutions will open space to bring in new ideas and contribute to the culture of learning. Providing satisfactory services to patients requires team work and involves teams and individuals of different expertise. Patient visits to hospitals usually come in contact with employees work in different medical and non-medical departments. Employees that come in contact with patients should receive new knowledge and instill it into the working systems. However, many developing healthcare systems face the problem of communication and coordination gap between different departments of the hospital $[4,39]$. A culture should be developed within the hospital where systems ingrained with new knowledge are well connected so that learning can be shared across the organization to enhance service quality.

Contextually, caution should be given to generalize the study findings in healthcare systems of other developing countries due to situational and cultural differences. Furthermore, the use of non-probability sampling to collect the data due to the unavailability of sampling frame is another limitation of the study [5]. Future studies should utilize similar variables and test their relationships in different healthcare settings and compare the findings of this study and observe the effect of situational factors and culture on learning organizational culture.

The findings of this current study and the existing body of evidence have approved that there are some associations between effective learning organization and certain extrinsic organizational practices. Indeed, embedded system like linkage of medical episodes, in medical and non-medical fields, have shown a positive impact among the sample in increasing knowledge-environment. Addition, building strong reliable health information system, especially for decision making throughout the hospital would increase the chances of knowledge transfer among health practitioner. The absence of building health learning organization may promote ineffective performance within a holistic healthcare system.

\section{Conclusions}

Learning culture can become a guiding tool for organizations to improve skills and knowledge of individuals and teams and develop a culture to work together and deliver quality services. Policy makers and the top leadership should work towards creating a sense of shared purpose among medical and non-medical staff at middle and lower level management. Well-connected systems embedded with learning culture will help to build effective relationships, coordinated actions and the reflections that strengthen the desirable practices in healthcare while correcting structures, procedures, and assumptions. In simple, leaderships of healthcare organizations can create a continuous learning environment.

This study demonstrated the usefulness of implementation of organizational learning practices based on several dimensions that can lead to transfer hospitals and healthcare institutions into learning organization during crisis.

\section{Abbreviations}

SA: Saudi Arabia; MOH: Ministry of Health; TUH: Teaching University Hospital; SGH: Semi-governmental Hospital; PH: Private Hospital; CL: Continuous Learning; DI: Dialogue and Inquiry; TC: Team Learning and Collaboration; ES: Embedded Systems; EM: Empowerment; SE: Systems Connections; SL: Learning Organization Culture; MLR: Multiple Leaner Regression

\section{Acknowledgements}

The author extends his appreciation to the Deanship of Scientific Research, King Saud University and the Research Center at the College of Business Administration for supporting this project.

\section{Author's contributions}

W.A wrote the whole manuscript. The author(s) read and approved the final manuscript.

\section{Authors' information}

Wadi is an Associate Professor in the Department of Health Administration, King Saud University.

\section{Funding}

Not externally funded.

\section{Availability of data and materials}

All data are available based on academic purposes through the corresponding author (waalonazi@ksu.edu.sa).

\section{Declarations}

Ethics approval and consent to participate

This study has been performed in accordance with the Declaration of Helsinki and was approved by an appropriate ethics committee in Ministry of Health (General Directorate of Health Affairs IRB A-220), Riyadh, Saudi Arabia. No consent form was used, as replying to the online survey implied agreement to participate. The committee in the General Directorate of Health Affairs approved this procedure. 


\section{Competing interests}

The author declares that he has no financial or personal relationships that may have inappropriately influenced him in writing this article.

Received: 22 December 2020 Accepted: 23 April 2021

Published online: 04 May 2021

\section{References}

1. Ghaffar A, Gilson L, Tomson G, Viergever R, Røttingen J-A. Where is the policy in health policy and systems research agenda? Bull World Health Organ. 2016;94:306. https://doi.org/10.2471/BLT.15.156281.

2. Donabedian A. The methods and findings of quality assessment and monitoring: an illustrated analysis. 1985; Health Administration Press.USA.

3. Peirce JC. The paradox of physicians and administrators in health care organizations. Health Care Manage Rev. 2000;25:7-28. https://doi.org/10.1 097/00004010-200001000-00002.

4. Leufvén M, Vitrakoti R, Bergström A, Ashish K, Målqvist M. Dimensions of Learning Organizations Questionnaire (DLOQ) in a low-resource health care setting in Nepal. Health Res Policy Syst. 2015;13:6. https://doi.org/10.1186/14 78-4505-13-6.

5. Alonazi WB. Exploring shared risks through public-private partnerships in public health programs: a mixed method. BMC Public Health. 2017;17:571. https://doi.org/10.1186/s12889-017-4489-z.

6. Goh SC, Chan C, Kuziemsky C. Teamwork, organizational learning, patient safety and job outcomes. Int J Health Care Qual Assur. 2013;26(5):420-32. https://doi.org/10.1108/IJHCQA-05-2011-0032.

7. Krejci JW. Imagery: stimulating critical thinking by exploring mental models. J Nurs Educ. 1997;36(10):482-4

8. Egan TM, Yang B, Bartlett KR. The effects of organizational learning culture and job satisfaction on motivation to transfer learning and turnover intention. Hum Resour Dev Q. 2004;15:279-301. https://doi.org/10.1002/ hrdq.1104.

9. Preskill H, Torres RT. The role of evaluative enquiry in creating learning organizations. Organizational Learning and The Learning Organization. 1999 Sage Publications, Newbury Park, CA

10. Hofstede G. Attitudes, values and organizational culture: Disentangling the concepts. Organ Stud. 1998:19:477-93. doi:https://doi.org/10.1177/017084 069801900305

11. Jiménez-Jiménez D, Sanz-Valle R. Innovation, organizational learning, and performance. J Bus Res. 2011;64(4):408-17.

12. Wang $X$, Yang B, McLean GN. Influence of demographic factors and ownership type upon organizational learning culture in Chinese enterprises. Int J Train Dev. 2007;11(3):154-65. https://doi.org/10.1111/j.1468-2419.2007. 00278.x.

13. Joo BK, Park S. Career satisfaction, organizational commitment, and turnover intention. Leadersh Organ Dev J. 2010;31(6):482-500. https://doi.org/10.12 691/education-2-9-14.

14. Carroll JS, Edmondson AC. Leading organisational learning in health care. Qual Saf Health Care. 2002;11(1):51-6. https://doi.org/10.1136/qhc.11.1.51.

15. Ratnapalan S, Uleryk E. Organizational learning in health care organizations. Systems. 2014;2:24-33. https://doi.org/10.3390/systems2010024.

16. Moore G, Todd A, Redman S. Strategies to increase the use of evidence from research in population health policy and programs: a rapid review; NSW Health: 2009

17. Senge PM. The art and practice of the learning organization. New York: Doubleday; 1990.

18. Gomes G, Wojahn RM. Organizational learning capability, innovation and performance: study in small and medium-sized enterprises (SMES). Rev Adm. 2017;52(2):163-75. https://doi.org/10.1016/j.rausp.2016.12.003.

19. Halim A, Ahmad H, Ramayah T, Hanifah H, Taghizadeh K, Mohamad N. Towards an innovation culture: Enhancing innovative performance of Malaysian SMEs. Acad J Interdiscip Stud. 2015;4,(2):85-94. https://doi.org/10. 5901/ajis.2015.v4n2p85.

20. Reardon L, Davidson E. An organizational learning perspective on the assimilation of electronic medical records among small physician practices. Eur J Inf Syst. 2007;16:681-94. https://doi.org/10.1057/palgrave.ejis.3000714

21. Tucker L, Nembhard M, Edmondson C. Implementing new practices: An empirical study of organizational learning in hospital intensive care units. Manag Sci. 2007;53(6):894-907. https://doi.org/10.1287/mnsc.1060.0692.

22. French $\mathrm{B}$, Thomas $\mathrm{LH}$, Baker $\mathrm{P}$, Burton $\mathrm{CR}$, Pennington $\mathrm{L}$, Roddam $\mathrm{H}$. What can management theories offer evidence-based practice? A comparative analysis of measurement tools for organisational context. Implementation Sci. 2009;4(28):1-15. https://doi.org/10.1186/1748-5908-4-28.

23. Secundo G, Toma A, Schiuma G, Passiante G. Knowledge transfer in open innovation. Bus. Process Manag J. 2019;25(1):144-63. https://doi.org/10.1108/ BPMJ-06-2017-0173.

24. Antonacopoulou EP, Sheaffer Z. Learning in crisis: Rethinking the relationship between organizational learning and crisis management. J Manag Inq. 2014;23(1):5-21. https://doi.org/10.1177/1056492612472730.

25. Ammar A, Chtourou H, Boukhris O, Trabelsi K, Masmoudi L, Brach M, et al. Covid-19 home confinement negatively impacts social participation and life satisfaction: A worldwide multicenter study. Int J Env Res Pub He. 2020; 17(17):6237. https://doi.org/10.3390/ijerph17176237.

26. Alkhamis A. Health care system in Saudi Arabia: An overview. East Mediterr Health J. 2012;18(10):1078-80.

27. Kelly L, Harlock J, Peters M, et al. Measures for the integration of health and social care services for long-term health conditions: a systematic review of reviews. BMC Health Serv Res. 2020;20:358. https://doi.org/10.1186/s12913020-05206-5.

28. Alonazi WB. Fraud and Abuse in the Saudi Healthcare System: A Triangulation Analysis. Inquiry. 2020;57:1-8. https://doi.org/10.1177/004 6958020954624

29. Reponen E, Rundall TG, Shortell SM, et al. Benchmarking outcomes on multiple contextual levels in lean healthcare: a systematic review, development of a conceptual framework, and a research agenda. BMC Health Serv Res. 2021;21:161. https://doi.org/10.1186/s12913-021-06160-6.

30. Wald HS. Optimizing resilience and wellbeing for healthcare professions trainees and healthcare professionals during public health crises-Practical tips for an 'integrative resilience'approach. Med Teach. 2020;42:744-55. https://doi.org/10.1080/0142159X.2020.1768230.

31. Alonazi WB. The Impact of Emotional Intelligence on Job Performance During COVID-19 Crisis: A Cross-Sectional Analysis. Psychol Res Behav Manag. 2020;13:749-757. https://doi.org/10.2147/PRBM.S263656.

32. Marsick VJ, Watkins KE. Demonstrating the value of an organization's learning culture: the dimensions of the learning organization questionnaire. Adv Dev Hum Resour. 2003;5(2):132-51. https://doi.org/10.1177/1523422303 005002002.

33. Hair F, Hult M, Ringle C, Sarstedt M. A primer on partial least squares structural equation modeling (PLS-SEM); Sage publications, 2016.

34. Kruk ME, Freedman LP. Assessing health system performance in developing countries: a review of the literature. Health Policy. 2008;85(3):263-76. https:// doi.org/10.1016/j.healthpol.2007.09.003.

35. Durrani, H. Healthcare and healthcare systems: inspiring progress and future prospects. Mhealth. 2016; 2.(3) doi: https://doi.org/10.3978/j.issn.2306-9740.2 016.01.03.

36. Pennel CL, McLeroy KR, Burdine JN, Matarrita-Cascante D. Nonprofit hospitals' approach to community health needs assessment. Am J Public Health. 2015;105(3):e103-13. https://doi.org/10.2105/AJPH.2014.302286.

37. Kennith TS. Bureaucracy Is Keeping Health Care from Getting Bette. Harvard Business Review. 2017; retrived on 3 March 2021 from https://hbr.org/201 7/10/bureaucracy-is-keeping-health-care-from-getting-better

38. Andreasson J, Ljungar E, Ahlstrom L, Hermansson J, Dellve L. Professional bureaucracy and health care managers' planned change strategies: Governance in Swedish Health Care. Nordic J Working Life Stud. 2018;8.(1): 23-41. https://doi.org/10.18291/njwls.v8i1.104849.

39. Wang $X$, Birch $S$, Zhu W, et al. Coordination of care in the Chinese health care systems: a gap analysis of service delivery from a provider perspective. BMC Health Serv Res. 2016;16:571. https://doi.org/10.1186/ s12913-016-1813-8.

\section{Publisher's Note}

Springer Nature remains neutral with regard to jurisdictional claims in published maps and institutional affiliations. 